\title{
PIONEER
}

VOLUME 10, Issue 2, December 2018: 124 - 137

\section{GENDER STEREOTYPES IN THE FIVE YEAR ENGAGEMENT MOVIE}

\author{
Latifatus Zuhro \\ University of Abdurachman Saleh Situbondo \\ latifatuszuhro14@gmail.com
}

\begin{abstract}
Gender stereotypes are broad categories which reflect the impressions and beliefs about appropriate behavior for women and men. The issue of gender stereotypes still exists today, and the society wants to understand that gender stereotypes can have an important influence on career and relationships. The data in this research were in the form of dialogues, and behaviours of characters in The Five Year Engagement movie. This research was done by analyzing the data qualitatively. The steps of data analysis consisted of sorts the data that were related with gender stereotypes theory, classified the scenes of dialogue and behavior, and described how gender stereotypes were reflected based on the types of basic kinds and types of stereotypes based on the role in The Five Year Engagement movie. The result of the research described basic kinds of gender stereotypes, there were four data indicated personality traits, five data for domestic behaviours, two data for occupation, and four data for physical appearance. Then, these data were classified into types of gender stereotypes based on the roles, there were seven data for masculinity, five data for feminity, and five data found of androgyny. Based on the analysis, the dominant types of gender stereotypes based on the roles was masculinity which had eight data.
\end{abstract}

Keywords: gender, stereotypes, gende roles

\section{INTRODUCTION}

Movie was the only area, which depicts the people, though they were of any class (poor, middle \& rich) along with the predicament and happiness. Such depiction makes literatures look more realistic and touchy. Movie also capture the same like literature but due to its visual and sound effect, it got wide popularity (Ramrao, 2016). Movie was a form of media that can influence stereotypes in society include gender seteotypes. Movie also capture the symptoms and changes that happened in society which re-presented to the society to get appreciation. One of the most important topics that were often discussed abroad, especially in America and Europe was gender and sexuality which applied into movies. One of movies which reflected about gender was The Five Year Engagement by Nicholas Stoller.

The Five Year Engagement was movie directed by Nicholas Stoller, and written by Jason Segel and Nicholas Stoller. The movie told about the gender stereotypes of society that was very influential on career, family, and even relationship, like a couple whose relationship becomes strained when their engagement was continually extended caused their problem 
career, Violet's career was getting up and she became workaholic, whereas Tom's career was getting worse and he had more time jobless, while the society around them think that men should had better jobs than women, it adds to the complexity of their relationship.

Gender was the appearance and behavior of a person and how they see themselves. Gender was determined by the conception of tasks, functions and roles attributted to women and men in society and in public. So it could not be separated from the gender role and stereotypes that was inherent in the society's view. Gender was not a noun a 'being' - but a 'doing'. Gender was created and reinforced discurcifely, through talk and behavior, where individuals claim a gender identity and reveal it to others (West \& Zimmerman 1987 et al. 2009). According to Beasley in Putri (2017), gender typically refers to the social process of dividing up people and social practices along the lines of sexed identities.

According to Oxford English Dictionary (2018), stereotype was a "widely held but fixed and oversimplified image or idea of a particular type of person or thing”. Stereotypes were ubiquitous. Among other things, they cover racial groups, political groups, genders, demographic groups, and activities (Shleifer, 2015). One of the stereotypes was a gender. The topic analyzed by the researcher in this research.

Some previous studies on gender first used by Putri (2017). She studied about The Analysis of Gender Stereotypes in Bad Moms Movie. She focused on life of women that could gave equal authority based on their gender and she used Beasley's theory (2005). The second research was Queering The Construction of Gender Identity in Chris Colombus Movie Mrs. Doubtfire, a research by Agustina and Maimunah (2013), which focused on queering gender identity. They used Butler's theory (1999). The third was by Painter (2015). The study was about 'His Women' Problem: An Analysis of Gender on 'The Newsroom' in a drama series. He used Social Responsibility Theory (1947). In this study, he focused more on portrayal of female journalists in popular culture.

The differences of this study from the previous studies was on the data and the theory in this research. The researcher used The Five Year Engagement movie by Nicholas Stoller, and the theory by Beasley (2005). In this research, the researcher analyzed gender stereotypes. The researcher chose this topic because nowadays, issue of gender exist in popular culture and it could gave affect society's mindset and it could harmful if we left unchecked.

In this study, the analysis focused on gender stereotypes and based on the role represented in The Five Year Engagement movie by Nicholas Stoller. The researcher used Beasley's theory (2005). There were seven characters in the movie who analyzed. They were Tom Solomon, Violet Barnes, Alex Eilhauer, Suzie Barnes, Chef Sally, Billy, and George 
Barness. The researcher chose gender stereotypes as a term because the issue of gender stereotypes still exists today, and the society would understand that gender stereotypes could had an important influence on career and relationships, such as discrimination toward one gender, and that was detrimental. Movie was chosen because the movie as one of the popular media today that could apply the story in the movie toward real life. While The Five Year Engagement movie would be examined because this movie contains about the stereotypes gender depictions in the society.

\section{REVIEW OF LITERATURE}

\section{Gender}

Gender was a socially constructed definition of women and men. It was the social design of a biological sex, determined by the conception of tasks, functions and roles attributed to women and men in society and in public and private life. It was a culture specific definition of femininity and masculinity and therefore varies in time and space (Council of Europe). According to Moore in Musawa (2014), gender is different from sex and sex of men and women biologically. The term gender was put forward by scientists social with the intent to explain the differences of women and men who had inherent traits and formations culture. Gender was the difference in roles, functions, and responsibilities between men and women who were the result of construction social and changeable according to the times.

According to Beasley (2005): 'Gender' typically refers to the social process of dividing up people and social practices along the lines of sexed identities. The gendering process frequently involves creating hierarchies between the divisions it enacts. One or more categories of sexed identity are privileged or devalued.

\section{Gender Stereotypes}

According to Begley in Putri (2017), gender stereotypes are very influential, they affect conceptualization of women and men and establish social categories for gender. These categories represent what people think, and even when beliefs vary from reality, the beliefs can be very powerful forces in judgments of self and others.

Basic Kinds of Gender Sterotypes There are four types of gender stereotype (Parenthood, 2018):

1. Personality Traits: Personality traits reflected people's characteristic patterns of thoughts, feelings, and behaviors. 
2. Personality Traits: Personality traits reflected people's characteristic patterns of thoughts, feelings, and behaviors.

3. Occupations: Women were supposed to had simple jobs. On the other hand, men were supposed to how more complicated jobs.

4. Physical appearance: Physical appearance of gender stereotypes was different depend on the culture in some place.

\section{Gender Role}

According to Baker in Krahn (2015), gender role stereotypes were characteristics of gender in traditional representations that draw differences between typical "feminine" behaviors from typical "masculine" behaviors in society . In addition, gender roles in society means how we were expected to act, speak, dress, groom, and conduct ourselves based upon our assigned sex. For example, girls and women were generally expected to dress in typically feminine ways and be polite, accommodating, and nurturing. Men were generally expected to be strong, aggressive, and bold. Every society, ethnic group, and culture had gender role expectations, but they could be very different from group to group. They could also change in the same society over time.

\section{Types of Gender Stereotypes Based on The Role}

There were types of gender stereotypes based on the role according to the Bem Sex Role Inventory (BSRI, 1974):

\section{a. Masculinity}

When we were talking about men, of course we were talking about a social constructed and ever changing gender identity. Masculinity refers to behaviour and culture associated with men, and the different ways of being men. Masculinity was seen to be the trait which emphasizes ambition, acquisition of wealth, and differentiated gender roles. According to Hofstede in Culture's Consequence (2001), masculinity stands for a society in which social gender roles are clearly distinct: "Men are supposed to be assertive, tough, and focused on material success". Masculinity was gender concepts of socially constructed behavior and in relation to men. Masculinity contained the value of competitiveness, firmness, materialistic, ambition and strength. 


\section{b. Feminity}

According to Hofstede in Culture's Consequence (2001), Feminity stands for a society in which social gender roles overlap: Both men and women are supposed to be modest, tender, and concerned with the quality of life. Society expects that women must be pretty, beautiful, sexy and hot, they should not work, they should be able to cook. She also must be 'ladylike', and then should be a great mother (Sherrie, 2017).

\section{c. Androgyny}

Androgyny was a term in a gender identity in which a person was not clearly included into the masculine and feminine roles that exist in society. Many androgyny were identified to be between men, women, and were also called genderless. An androgynous person is someone who can be both independent and sensitive to the needs of others, aggressive and yielding, tough and tender, depending on the situational appropriateness of these various behaviors. A woman can be both a loving mother and an ambitious executive; conversely, a man is not a "sissy" if he enjoys the theater or cooking (Dhankar, 2010).

\section{Characters}

According to Mandikdasmen in Yana (2013), character is a way of thinking and behaving that characterizes each individual to live and work, both within the family, community, nation and state. Commonly, people see a character in a novel or movie through the character trait. Character trait is a personality characteristic or inherent value that someone has which they are unlikely to change and that helps to make an individual into the kind of person he is (Your Dictionary, 2018).

\section{Movie}

Movie was a popular media which were used not only for delivering messages, but also channeling views to the general public. Movie was a mixed medium of various technologies and elements art and collaborated from the development of photography technology and sound recordings were also from various arts of fine art, theater, literature, architecture to music. Asnawir and Usman in Margono (2010) said that movie is motion picture as a form of entertainment or an art, usually preceded by showing of one or move motion picture. According to Cambridge English dictionary (2018), movie is a series of moving pictures often telling a story, usually shown in a theater or on television. 


\section{METHOD}

This was a qualitative research. Qualitative research was a means to explore and understood the indviudal or groups ascribe to a social or human problem (Cresswell, 2009). Through qualitative research, we could explore a wide array of dimensions of the social world, including the texture and weave of everyday life, the understandings, experiences and imaginings of our research participants, the ways that social processes, institutions, discourses or relationships work, and the significance of the meanings that they generate, we could do all of this qualitatively by using methodologies that celebrate richness, depth, nuance, context, multi-dimensionality and complexity rather than being embarrassed or inconvenienced by them (Mason, 2002). The researcher analyzed gender stereotytypes and gender stereotypes based on the role in The Five Year Engagement movie used Qualitative method.

The researcher chose The Five Year Engagement movie directed by Nicholas Stoller as the data source of this research. The research data in this research were in the form of dialogues and behaviours of the characters in The Five Year Engagement movie, the researcher analyzed gender stereotypes and gender stereotypes based on the role of the movie. The instruments of the research was the researcher herself as the subject of the research who does the steps of the research as above in the technique of data analysis. For example, by watching the movie and anlayzing the data to find out connection that related to the subject of the research.

The researcher used four steps of Miles and Huberman's theory (2007) on data analysis, these were data reduction, data reduction refer to the process of selecting, focusing, simplifying, abstracting, and transforming the data that appear in written up field notes or transcriptions. In this step, the researcher sorted the data that were related with gender stereotypes theory. The second is data display, A display was an organized, compressed assembly of information that allows conclusion drawing and action. They described many forms of data display, illustrated with examples of actual data. In this step, the researcher classified the scenes of dialogue and behavior based on the data after the researcher watched The Five Year Engagement movie. and the last is conclusion drawing. The researcher classified and analyzed the collected data based on the basic kinds of gender sterotypes and types of gender stereotypes based on the role by Beasley (2005) on gender steotypes. Further, the research described how gender stereotypes are reflected based on the types of basic kinds and types of stereotypes based on the role in The Five Year Engagement movie. 


\section{FINDINGS AND DISCUSSION}

\section{Findings}

In this research, the researcher found fifteen data determined into four basic kinds of gender stereotypes. There were four data indicated personality traits, five data for domestic behaviours, two data for occupation, and four data found of physical appearance. The details can be seen in Table 1.

Table 1. Basic Kinds of Gender Stereotypes Found

\begin{tabular}{clc}
\hline No & $\begin{array}{c}\text { Basic Kinds of } \\
\text { Gender Stereotypes }\end{array}$ & Frequency \\
\hline 1. & Personal Traits & 4 \\
\hline 2. & Domestic Behaviors & 5 \\
\hline 3. & Occupation & 2 \\
\hline 4. & Physical Appearance & 4 \\
\hline
\end{tabular}

Then, these data were classified into types of gender stereotypes based on the roles. They were seven data indicating masculinity, five data for feminity, and three data found of androgyny.

Table 2. Gender Stereotyoes based on the Roles

\begin{tabular}{clc}
\hline No & $\begin{array}{l}\text { Gender Stereotypes } \\
\text { Based on the Roles }\end{array}$ & Frequency \\
\hline 1. & Masculinity & 7 \\
\hline 2. & Feminity & 5 \\
\hline 3. & Androgyny & 3 \\
\hline
\end{tabular}

\section{Examples of the data found:}

\section{a. Masculinity}

Based on basic gender stereotypes on Parenthood (2018), masculinity could be seen from four characteristics: personality traits, domestic behaviour, occupation, and physical appearance. First, personality traits of men were expected to be agressive, to be thought, self confident, and dominant. Men were messy and lazy. The second was domestic behavior of men 
were all behavior related to the household repairs. Men could not cook, and they could not take care of children. The third was occupations. Men were supposed to do hard jobs, like engineering, and construction workers. Men could also all good at Math. They should made more money than women, and they better to be a leader. The last, the physical appearance of gender stereotypes is different, it depends on the cultures in particular places. Men were expected to be tall and broad-shouldered, men also get into fights. In conclusion, any male or female character who had such the characteristics were considered to had "masculinity" side.

\section{Character : Winton}

Winton was a professor of psychology in campus where Violet study. He was a hard worker and ambitious. In The Five Year Engagement movie, he was a typical person who used his position for his personal interests.

Datum 01

- Situational context : In class, Winton explain and show some experiments to students. Winton was a professor of psychology.

- Winton was a professor of psychology.

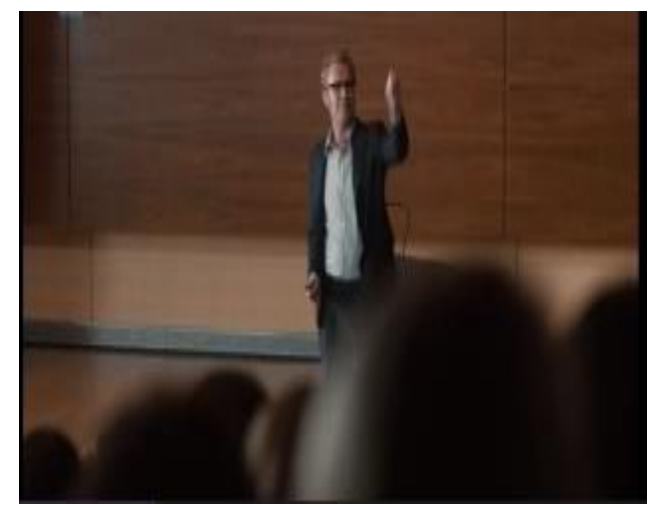

Figure 1. Winton was a professor of psychology

- $\quad$ Time :00.30.04

- $\quad$ Basic kind of gender stereotype : occupation

This scene showed that Winton's profession was a professor of psychology. Professor was one of occupation.

- Type of gender stereotype based on the role: masculinity According to Parenthood's theory (2018), "men are supposed to how more complicated jobs, men are better doctors". Therefore, Winton had characteristics of masculinity. 


\section{b. Feminity}

The behaviour of characters consisted of feminity. Based on basic gender stereotypes, feminity could be determined from four criteria, they were personality traits, domestic behaviour, occupation, and physical appearance. First, personality traits of women were expected to be passive and submissive. Women were supposed to be shy. The second was domestic behavior of women were all behavior related to the household such as cook, do housework, and child care was considered best done by women. The third was occupations, women were supposed to do simple jobs, like nurses and secretaries were usually women, women could not be presidential candidates. The last, the physical appearance of gender stereotypes was different, depending on the cultures in some places. Women were expected to be small and graceful. The appearances of women should be appearances something feminine.

\section{Character : Tom}

Tom was a main character. He was Violet's fiance. He was a chef in a famous resaurant in San Fransisco. But he chose to move to Michigan following Violet and worked in a smaller restaurant that made him frustrated.

Datum 01

- Situational context : in a evening party, when Tom and Violet met for the first time, Tom was wearing a pink bunny costume.

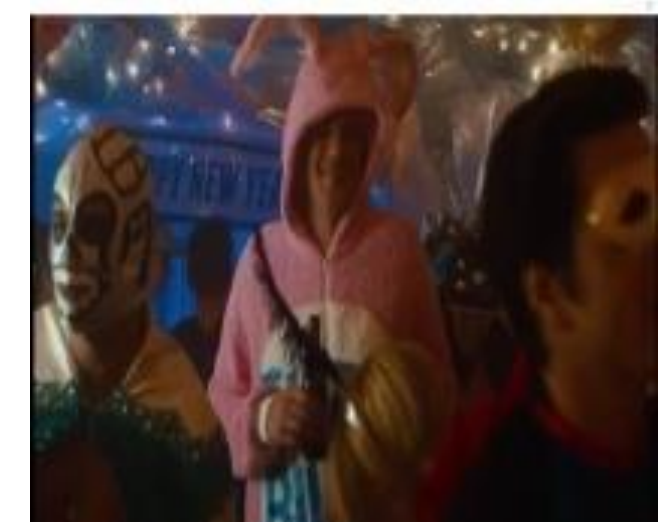

Figure 2. Tom was wearing a pink bunny costume

\section{c. Androgyny}

An androgynous person was someone who could be both independent and sensitive to the needs of others, aggressive and yielding, tough and tender, depending on the situational 
appropriateness of these various behaviors. A woman could be both a loving mother and an ambitious executive; conversely, a man was not a "sissy" if he enjoys the theater or cooking (Dhankar: 2010).

Character : Billy

Billy was one of minor characters in The Five Year Engagement movie. He was friend of Violet and Tom. He was typical men who loved his family.

Datum 01

- Situational context : In a afternoon, Billy was knitting sweaters in the living room.

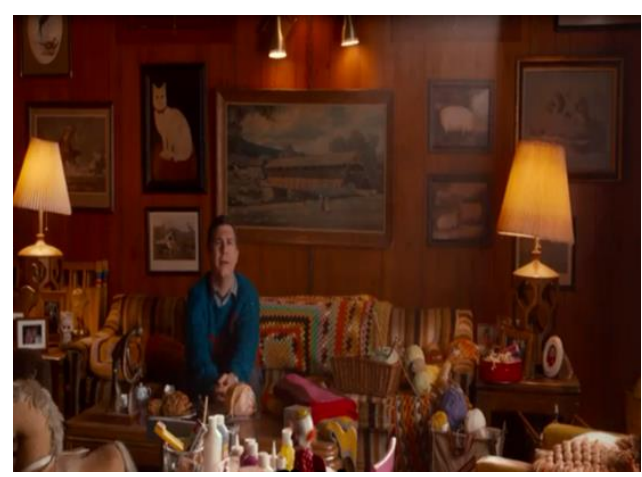

Figure 4.10 Billy was knitting sweater

- $\quad$ Time :00.49.20

- Basic kind of gender stereotype : domestic behavior

The behavior showed that Billy like to spend his time at home and knitting sweaters. The activity of knitting shows that Billy had feminine characteristic.

\section{Discussion}

Gender stereotypes based on the roles were classified from four basic, according to Parenthood, 2018, there were personality traits, domestic behaviours, occupation, and physical appearance. From the data classification and analysis in the research findings, the researcher found sixteen data determined into four basic kinds of gender stereotypes. There were four data indicating personality traits, five data for domestic behaviours, two data for occupation, and five data found of physical appearance.

Then, these data were classified into three types of gender stereotypes based on the roles according to theory by Bem Sex Role Inventory (1974). They were eight data indicating masculinity, five data for feminity, and three data found of androgyny. The gender stereotypes based on the role were represented by the characters from their behaviors, and dialogues. The 
first type was masculinity characteristics of the characters in The Five Year Engagement movie. Based on data findings, some characters contained characteristics of masculinity. They were Violet, Winton, Alex, and chef Selly. The women's characters also had masculine side usually called 'women's masculinity'. Such as Violet, her personality traits, occupation, and physical appearance, like when Violet hurriedly went to campus and looked very busy, while Tom was cooking for their breakfast, her domestic behaviour that showed her masculine. According to Hofstede in Culture's Consequence (2001), masculinity stands for a society in which social gender roles were clearly distinct: "Men are supposed to be assertive, tough, and focused on material success". From the theory, it could be classified from Violet behaviour, she more focused on material success like man's characteristic, she did not do housework. The reason why Violet more dominant to masculine was because her background family, her mother raised her with hard education. She made Violet become a strong women as not to be weak like her when she had to divorce Violet's dad. Then, Chef Selly who would never married, because she showed her personality traits with her mindset about marriage was so bad. She belongs to masculine because her bad relationship in the past made her masculine characteristics.

From the analysis, types of gender stereotypes based on the role was more dominant to masculinity. While basic kinds of gender stereotypes found more dominant to physical appearance, because someone could know someone's gender role from their physical appearance without knew more their personal traits, domestic behaviours, and occupation.

Some behaviors and dialogues in The Five Year Engagement movie showed feminity. In the movie, only a women that contained feminity. She was Suzie, her personality traits which showed her sensitive feelings, she was crying in Violet and Tom's engagement. For domestic behavior was reflected when she was motherhood and enjoy spend her time at home with her chilldrens. Besides women, there was a man who had masculinity characteristics. He was Tom, he was reflected by the personality traits, domestic behavior, occupation, and physical appearance. It could be seen when he wearing pink super bunny, he was crying, and he was cooking some food for their breakfast.

The last was Androgyny, there were some behaviors and dialogues that contained the characteristics of androgyny. An androgynous person was someone who could be both independent and sensitive to the needs of others, aggressive and yielding, tough and tender, depending on the situational appropriateness of these various behaviors. They could did two types of gender stereotypes which combined masculinity and feminity. He or she could did something that should be related with women or men without leaving their characteristics. In The Five Year Engagement movie who could combined two types of gender stereotypes 
without leaving the characteristic was Billy. He liked knitting sweater, and sometimes, Billy and friends hunted in a forest, but the other side, they wearing sweaters that Billy knitted, then the sweater made them look like feminine. The behavior showed Billy's androgyny characteristic. Billy's character inclined to androgyny, because basically he was a feminine men. He likes and could did women's activities, without leaving his activities as a men, such as his hobby and responsibility to his family.

The researcher found some differences from the previous studies that look The Five Year Engagement movie as the some studies with the same content compared to her study to be analyzed. The first, this research compared to Putri's research (2017). She studied about The Analysis of Gender Stereotypes in Bad Moms Movie. She focused on life of women that could gave equal authority based on their gender and she used Beasley's theory (2005). Beside that, there was a difference in a research findings that was masculinity more dominant in the characters analyzed. While in Putri's research, gender stereotypes was reflected based on types of the role in Bad Moms movie and found feminity was more dominant in the characters that analyzed .

The second of previous studies was An Analysis Of Gender Stereotypes and Performativity in Brave Movie, a research by Umastuti (2015).

The main finding of the research in these gender stereotypes vary in some types, such as duties, roles and responsibilities. While, this research findings found gender stereotypes based on the role which found three types. There were masculinity, feminity, and androgyny.

The third was by Dysart (2015). The study was about Gender Roles And Stereotypes Revealed In Recent Best-Selling Adolescent Literature: A Content Analysis. The study discussed gender roles stereotypes in three best-selling books. The findings were the traditional and progressive male, and female gender roles, and stereotypes including both major and minor themes. While, this research found gender stereotypes based on basic and based on the roles.

Importantly, the similiar thing of this research and the three previous studies was the research had same purpose, that was man and female should not be afraid of being themselves even if it means not fitting into a traditional male and female gender role or stereotype. We want society to be aware of the gender roles and stereotypes in the world around them.

\section{CONCLUSION AND SUGGESTION}

\section{Conclusion}

Based on the analysis of gender stereotypes in The Five Year Engagement movie, the researcher found sixteen data determined into four basic kinds of gender stereotypes. There 
were four data indicating personality traits, five data for domestic behaviours, two data for occupation, and five data found of physical appearance. Then, these data were classified into types of gender stereotypes based on the roles. They were eight data indicating masculinity, five data for feminity, and three data found of androgyny. Masculinity more dominant in the characters that analyzed in this research.

\section{Suggestion}

This research only presented the proof and understanding of the behaviour of characters in The Five Year Engagement movie. The findings of this research were expected to give understanding to the society about gender stereotype in our surroundings. The reader could be aware how society expected about gender could give influence to many aspects in our life. Such as career, relationship, physical appearance, and occupation. Here some suggestion from the researcher related to gender stereotypes. The research about gender stereotypes in a movie still had room for further research, such as research with theory with other experts, and research with different research data. The next researcher could do research on the issues with different focus. The next researcher could focused to the androgyny gender.

\section{REFERENCES}

Agustina. \& Maimunah, S. (2013). Queering The Construction of Gender Identity in Chris Colombus Movie Mrs. Doubtfire. Surabaya: University of Airlangga.

Beasley, C. (2005). Gender and Sexuality. California: SAGE Publication Inc.

Bem, S. L. (1974). The Measurement of Psychological Androgyny. Journal of Consulting and Clinical Psychology.

Creswell, J.W. (2009). Research Design: Qualitative, Quantitative, and Mixed Methods Approaches (3rd ed). Los Angeles: SAGE Publication.

Dhankar, R. (2010). Androgyny. Journal of Gender. Retrieved April 22, 2010, from Percipio Thoughts.

Hofstede, G. (2001). Culture's Consequence (2nd ed). Netherlands, Tilburg University. SAGE PublicationS Inc.

Mason, J. (2002). Qualitative Researching. London: SAGE Publications Inc.

Miles, M. B. \& Huberman, A. M. (1984). Qualitative Data Analysis: A Sourcebook of New Methods. California; SAGE publications Inc.

Mulia, S.M. (2004). Islam Menggugat Poligami. Jakarta: Gradedia Pustaka Utama. Cet. I. 
Krahn, Kayla Marie. (2015). Reel Women: Gender Stereotypes in Film. Master's Theses and Doctoral Dissertations Eastern Michigan University.Painter, C. (2015). 'His Women' Problem: An Analysis of Gender on 'The Newsroom'. University of Dayton .

Parenthood, P. (2018). What Are Gender Roles and Stereotypes?. Planned Parrenthood Federation of America Inc.

Putri , M. H. (2017). The Analysis of Gender Stereotypes in Bad Moms Movie. (Unpublished Thesis). University of Abdurachman Saleh Situbondo.

Ramrao, T.N. (2016). Film and Literature: An Overview. Epitome Journals, 2. Retrieved September 9, 2018 from http://www.epitomejournals.com /VolumeArtic les/FullTextPDF/175_Research_Paper.pdf.

Sherrie, H. (2017). What it Takes to be a Perfect Woman in Today's Society. Life Advancer. Retrieved June 11, 2017, fromhttps://www.lifeadvancer.com/perfect-woman-society 